2. Mekkaoui C, Huang S, Chen HH, Dai G, Reese TG, Kostis WJ et al. Fiber architecture in remodeled myocardium revealed with a quantitative diffusion CMR tractography framework and histological validation. J Cardiovasc Magn Reson 2012; 14: 70.

3. Healy LJ, Jiang Y, Hsu EW. Quantitative comparison of myocardial fiber structure between mice, rabbit, and sheep using diffusion tensor cardiovascular magnetic resonance. J Cardiovasc Magn Reson 2011; 13: 74.

4. Toussaint N, Stoeck CT, Schaeffter T, Kozerke S, Sermesant M, Batchelor PG. In vivo human cardiac fibre architecture estimation using shapebased diffusion tensor processing. Medical Image Analysis 2013; 17: 1243-55.

5. Wei H, Viallon M, Delattre BM, Wang L, Pai VM, Wen H et al. Assessment of cardiac motion effects on the fiber architecture of the human heart in vivo. IEEE Trans Med Imaging 2013; 32: 1928-38.

\section{Adrenal Cystic Lymphangioma}

\section{The Editor}

Sir,

A previously healthy five-year old boy was evaluated for intermittent abdominal pain lasting for six months. Physical examination was normal but abdominal ultrasonography revealed a $3.5 \times 4 \mathrm{~cm}$ lobulated cystic mass located in the right adrenal region. Laboratory results were all normal except for slightly elevated serum neuron-specific enolase [NSE] $(31.2 \mu \mathrm{g} / \mathrm{L})$. Magnetic resonance imaging evaluation reported the mass could be a simple adrenal cyst or cystic lymphangioma (CL). The patient was scheduled for laparoscopic exploration and excision of the mass. In the operating room, he was placed in the left semi-lateral position; a 10 -mm umbilical trocar and three additional 5-mm working ports were inserted. A vessel sealing device was used to open the peritoneum, to dissect and completely excise the cyst (Figure). He was discharged home on the $2^{\text {nd }}$ postoperative day without any complication. During a one-year follow-up period, there was no cyst recurrence.

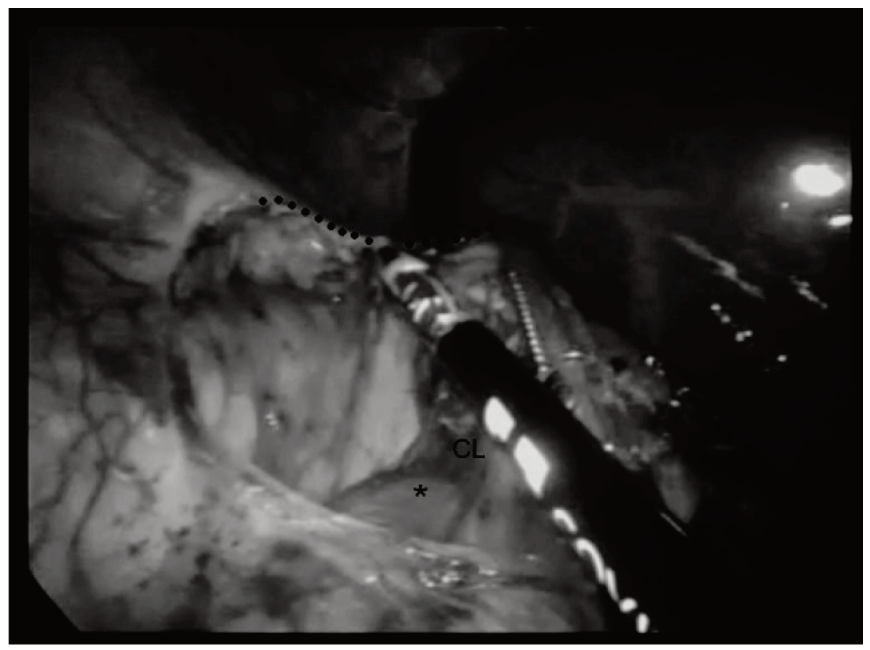

Figure: The peritoneum is opened and the retroperitoneum is reached with vessel sealing device. CL: cystic lymphangioma; asterisk: upper pole of right kidney; dotted line: cut edges of peritoneum
Cystic lymphangioma is a rare, congenital benign tumour, and most commonly reported in the head and neck regions. Intra-abdominal CL is rare (5-10\% of all cases), and can be located either intra- or retroperitoneal. Presumed percentage of the retroperitoneal lymphangiomas is approximately $1 \%$ of all intra-abdominal cases (1-3). Symptoms of an intraabdominal CL such as mild abdominal pain, nausea, and vomiting are neither pathognomonic nor specific to the pathology $(2,4,5)$.

Both ultrasonography and computed tomography (CT) are useful to diagnose CL and determine its extensions. Computed tomography assists the diagnosis of retroperitoneal lesion $(2,6)$. Magnetic resonance imaging is also a useful modality in assessing its extension $(3,7)$.

Management options of intra-abdominal CL include observation, drainage and sclerotherapy, laser therapy, irradiation, and surgical excision with laparotomy, laparoscopy assisted laparotomy and laparoscopy (4, 7-12). Since the reported complications and recurrence rates are very high in observed cases, in cases treated with drainage and sclerotherapy, or with irradiation, the preferred treatment of an abdominal CL is prompt and complete surgical excision, which should prevent recurrence (4).

Laparoscopic excision of the retroperitoneal CL in children is rarely reported in the literature $(5,9)$. According to a recent literature review, there are only three reported retroperitoneal CL cases which were successfully excised by laparoscopy in children, but none of them was located in the adrenal region (13). Although laparoscopic excision of a CL located in the adrenal gland region has not been reported previously, several laparoscopic approaches have been described to access the adrenal gland regions (14).

In our case, we preferred the transabdominal-transperitoneal way to reach the right adrenal gland region, and we found that laparoscopic excision of retroperitoneal CL in adrenal region is safe and effective with the help of a vessel sealing device. We report this rare case to draw attention to how laparoscopic excision is feasible even in such rare cases.

Keywords: Adrenal gland, cystic lymphangioma, laparoscopy, retroperitoneum

O Bosnall, S Moralıoğlu, AC Celayir

From: Zeynep Kamil Maternity and Children's Training and Research Hospital, Department of Pediatric Surgery, Istanbul, Turkey.

Correspondence: Dr O Bosnall, Zeynep Kamil Eğitim ve Araştırma Hastanesi, Çocuk Cerrahisi Servisi, 34668 Üsküdar, Istanbul, Turkey.E-mail:droktav@gmail.com

DOI: $10.7727 /$ wimj.2014.116 


\section{REFERENCES}

1. Kosir MA, Sonnino RE, Gauderer MWL. Pediatric abdominal lymphangiomas: a plea for early recognition. J Pediatr Surg 1991; 26: 1309-13.

2. Steyaert H, Guitard J, Moscovici J, Juricic M, Vaysse P, Juskiewenski S. Abdominal cystic lympahangioma in children: benign lesions that can have a proliferative course. J Pediatr Surg 1996; 31: 677-80.

3. Alqahtani A, Nguyen LT, Flageole H, Shaw K, Laberge JM. 25 years' experience with lymphangiomas in children. J Pediatr Surg 1999; 34: 1164-8.

4. Ryu WS, Kwak JM, Seo UH, Kim SH, Park SS, Kim CS et al. Laparoscopic treatment of a huge cystic lymphangioma: partial aspiration technique with a spinal needle. J Laparoendosc Adv Surg Tech 2008; 18: 603-5.

5. Wildhaber BE, Chardot C, Le Coultre C, Genin B. Total laparoscopic excision of retroperitoneal cystic lymphangioma. J Laparoendosc Adv Surg Tech 2006; 16: 530-3.

6. Konen O, Rathaus V, Dlugy E, Freud E, Kessler A, Shapiro A et al. Childhood abdominal cystic lymphangioma. Pediatr Radiol 2002; 32: 88-94.

7. de Lagausie P, Bonnard A, Berrebi D, Lepretre O, Statopoulos L, Delarue A et al. Abdominal lymphangiomas in children: interest of the laparoscopic approach. Surg Endosc 2007; 21: 1153-7.

8. Tan Y, Ong H, Chan W, Yap C, Wong W. Endoscopic ultrasound diagnosis and laparoscopic excision of an omental lymphangioma. J Laparoendosc Adv Surg Tech 2005; 15: 630-3.

9. Singh RR, Govindarajan KK, Bowen C, Chandran H. Retroperitoneal cystic lymphangioma: a rare presentation in childhood, treated laparoscopically. J Laparoendosc Adv Surg Tech 2009; 19: 249-50.

10. Esposito C, Alicchio F, Savanelli A, Ascione G, Settimi A. One-trocar Ileo-colic resection in a newborn infant with a cystic lymphangioma of the small-bowel mesentery. J Laparoendosc Adv Surg Tech 2009; 19: 447-9.

11. Solari V, Mullassery D, Lansdale N, Jesudason EC. Laparoscopic excision of a retroperitoneal lymphatic malformation in a newborn. J Pediatr Surg 2011; 46: E15-7.

12. Yagihashi Y, Kato K, Nagahama K, Yamamoto M, Kanamaru H. A case of laparoscopic excision of a huge retroperitoneal cystic lympangioma. Case Rep Urol 2011; 2011: 712520. doi: 10.1155/2011/712520.

13. Pampal A, Yagmurlu A. Successful laparoscopic removal of mesenteric and omental cysts in toddlers: 3 cases with a literature review. J Pediatr Surg 2012; 47: E5-E8

14. Tokar B, Bosnali O, Ilhan H, Demet D. Infragastric laparoscopic approach for the left adrenal gland region in children. Eur J Pediatr Surg 2011; 21: 140-1

\section{Closing the Gap between Preclinical Biologic Development and Clinical Application in Rheumatoid Arthritis}

The Editor,

Sir,

Rheumatoid arthritis (RA) is a chronic autoimmune disease; deferment and relapse of aggressive synovitis finally leads to destruction of joint cartilage and bone, and that is the main hazard of the disease. In recent years, biologic agents have become a hot spot of RA treatment research, owing to their higher specificity and fewer side effects than existing non-biologic disease-modifying and anti-inflammatory drugs. Although experimentally-induced arthritis models of rhesus monkeys are considered to be the closest model to the human RA disease (1), in the evaluation of preclinical biologic therapeutics, whether the disease also relapses in rhesus monkey models and the correspondent treatment efficacy in that condition were rarely studied. The reason for this phenomenon is that it was considered that induced-arthritis in rhesus monkeys is a monophasic course, and findings in previous studies also seemed to accord with this opinion: most common surrogate markers for the rhesus monkey model, ie clinical scoring, inflammatory and immunological markers, returned to the normal range within a typical follow-up time (70 days) after disease induction (2).

However, nowadays, in addition to the aforementioned traditional markers, a more sensitive imaging method, magnetic resonance imaging (MRI) with features of high soft-tissue resolution, multisection and multiparameter, has the unique advantage of being able to visualize the subclinical inflammatory synovium in clinical studies (3). In RA patients in remission according to the 28-joint Disease Activity Score-Creactive protein (DAS28-CRP), persistent active synovial inflammation detected by MRI is a high-risk predictor of subsequent joint destruction (4). Therefore, high-sensitivity MRI may give a deeper understanding in experimentally-induced arthritis in rhesus monkeys. In our previous study, we used MRI for dynamic evaluation of small hand joints in inducedarthritis models of rhesus monkeys treated with Celebrex (celecoxib). On day 90 after disease induction, MRI still revealed active synovitis in small hand joints in some monkeys (Figure), but common markers (ie clinical scoring and CRP) had returned to normal.

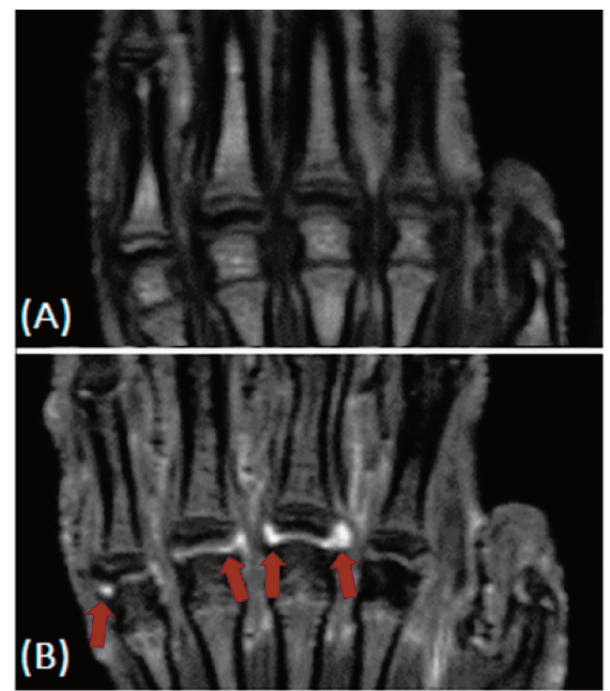

Figure: Magnetic resonance imaging (MRI) of small hand joints in rhesus monkeys with induced-arthritis.

Comparing the condition of pre-induction (A) and 90 days post-induction (B) rhesus monkey model in coronal enhanced T1-weighted images: before disease induction, the metacarpophalangeal joints (MCPs) were normal and there was non-enhancement in synovium; on 90 days post-induction, although most common markers of disease returned to normal: clinical scoring range within $0-1$ point and CRP value below $1 \mathrm{mg} / \mathrm{L}$, multiple active synovitis in MCPs (arrow) can still be found in MRI, indicating the continuous chronic activity in rhesus monkeys of induced-arthritis models after 90 days post-induction.

These data suggest that the sensitivity of conventional indicators may be insufficient, leading to a lack of awareness 